\title{
SUSTENTABILIDADE EMPRESARIAL/ AMBIENTAL NA FEIRA DO PARAGUAI: UM RELATO DE EXPERIÊNCIA A PARTIR DE PRÁTICAS EXTENCIONISTAS NA FACULDADE DE TECNOLOGIA E CIÊNCIAS EM VITÓRIA DA CONQUISTA-BA
}

\author{
Eliane Teixeira Assunção ${ }^{1}$ \\ Gardênia Tereza Jardim Pereira² \\ Glenda Felix Oliveira ${ }^{3}$
}

\section{RESUMO}

O perfil do profissional do futuro deve ser permeado pela característica da interdisciplinaridade atrelada ao pensamento sustentável. Para alcançar esse perfil é preciso aliar a teoria à prática e estender as atividades acadêmicas para além dos muros das faculdades, beneficiando assim a comunidade. Durante o período em que os microempreendedores da Feira do Paraguai receberiam o Centro de Comércio Popular em Vitória da Conquista, foi necessário levar até eles a preocupação com a sustentabilidade empresarial/ambiental, por meio da

\footnotetext{
${ }^{1}$ Graduada em Administração pela Universidade Estadual do Sudoeste da Bahia (UESB), pós graduada em Gestão de Pessoas pela Faculdade Juvêncio Terra (FJT), coordenadora do curso de Administração da Faculdade de Tecnologia e Ciências de Vitória da Conquista (FTC), e-mail: elianeassuncao.adm@hotmail.com

${ }^{2}$ Graduada em Turismo pela Faculdade de Tecnologia e Ciências, mestre em Cultura e Turismo pela Universidade Estadual de Santa Cruz (UESC), Coordenadora de pesquisa e extensão do Curso de Administração da Faculdade de Tecnologia e Ciências de Vitória da Conquista, e-mail: gardeniajardimftc@gmail.com

${ }^{3}$ Graduada em Direito pela Universidade Vale do Rio Doce, pós-graduada em Direito Público pelo Centro Universitário Newton Paiva, professora da disciplina Direito Empresarial do curso de Administração da Faculdade de Tecnologia e Ciências de Vitória da Conquista, e-mail: glendafelixadv@hotmail.com
} 
$1^{a}$ Mobilização em prol da Sustentabilidade Empresarial - Um conceito para toda a vida. A visão empresarial da sustentabilidade deve ser compreendida como investimento e não como gasto, portanto, não se afasta da ótica empresarial do lucro.

Palavras-chave: Empresário. Mobilização. Sustentabilidade Ambiental.

\begin{abstract}
The professional profile of the future must be permeated with the characteristic of interdisciplinarity linked to sustainable thinking. To reach this profile is necessary to combine theory with practice and extend the academic activities beyond the walls of college, benefiting the community. On the eve of microentrepreneurs in Paraguay received the Fair Trade Center Popular in Vitória da Conquista, is needed to bring them to concern about environmental corporate sustainability, by 1 st Mobilization in support of Corporate Sustainability - A concept for life. The corporate vision of sustainability should be taken as investment and not as an expense, therefore do not move away from the business viewpoint of profit.
\end{abstract}

Keywords: Businessman. Mobilization. Environmental sustainability.

\title{
Introdução
}

Ao considerar a importância do ensino superior para a formação profissional, deve também ser levada em conta a contribuição de disciplinas curriculares, que por meio do tripé pedagógico ensinopesquisa-extensão, possibilita a sensibilização de discentes, docentes e da sociedade civil em relação a problemas de ordem pública. Nesse sentido, é possível apontar que um dos assuntos atualmente mais discutidos no meio acadêmico seja a sustentabilidade empresarial/ambiental.

Acredita-se que por meio do ensino superior, a sensibilização em prol de ações que visem à preservação do meio ambiente deve alcançar o âmbito transversal e transdisciplinar. É importante que além do conhecimento teórico embutido nas grades curriculares, estejam presentes no cotidiano acadêmico práticas extensionistas voltadas à sustentabilidade ambiental. Afinal de contas, nos dias atuais, as 
mudanças na natureza, que deveriam acontecer de forma natural e gradativa, estão acontecendo rapidamente. Tal aceleração ocorre em virtude dos impactos causados pelo uso indevido dos recursos naturais e da exploração desmedida por parte das empresas, bem como pela falta de zelo, consciência e de atitude da sociedade na preservação ambiental. Esses fatos acabaram forçando a coletividade a repensar sua forma de relacionamento com o meio ambiente, fazendo com que as autoridades criassem e promovessem um novo conceito de consumo, o consumo sustentável.

Face à problemática em torno das questões ambientais e com a necessidade de mudanças no comportamento do homem contemporâneo, adveio a Política Nacional de Educação Ambiental no Brasil. O Art. $1^{\circ}$ da Lei n 9.795 (BRASIL, 1999) define a Educação Ambiental como a construção coletiva da sociedade pautada em valores, conhecimentos e relação de pertencimento que deve então contribuir para atitudes ecologicamente sustentáveis, e, consequentemente, para a preservação do meio ambiente.

Sendo assim, as contribuições para o bom e adequado uso dos recursos naturais passa a ser um dever de toda a sociedade organizada, sendo que recai no ensino superior uma responsabilidade significativa, haja vista que ao considerar a transversalidade e interdisciplinaridade eminente em toda e qualquer área de conhecimento, a comunidade acadêmica sensibilizada pode e deve corroborar para formação de profissionais/cidadãos sensibilizados, acarretando relações empresariais justas e conscientes.

Ponderaro cenário competitivo em que as empresas estão inseridas faz-se necessário para que haja reflexão acerca da responsabilidade socioambiental. Esta responsabilidade deve ser considerada não apenas como uma estratégia de marketing, mas sem dúvida, como prática que leve à manutenção real do meio ambiente. Portanto, cabe ao ensino superior, através das diretrizes curriculares estabelecidas, discutir junto à sociedade ações que contribuam para preservação do meio ambiente. É nessa perspectiva que se pretende apresentar o presente 
relato de experiência quanto às práticas extensionistas propostas pelas disciplinas Direito Empresarial e Meio Ambiente e Sociedade do curso de Administração da Faculdade de Tecnologia e Ciências em Vitoria da Conquista.

\section{Marco teórico}

É possível afirmar que modelos de gestão vigentes ainda tendem a práticas ortodoxas de administração pautadas na concepção de lucratividade, eficiência e eficácia organizacional, bem característico do modelo Taylorista no início do século XXI. Nesse contexto, Kotler (2000, p. 54) enfatiza que "a empresa está primordialmente interessada em maximizar o lucro". Todavia, já se tem feito claro em meio organizacional que para o alcance de metas e posicionamento no mercado altamente competitivo faz-se necessário pensar além da perspectiva eminentemente capitalista do lucro pelo lucro, mas na indissociabilidade entre lucro e responsabilidade socioambiental, visível a partir da década de 1990, quando houve um crescimento significativo de organizações que passaram a se preocupar com a produção, comercialização e consumo de bens e serviços de modo consciente.

Muitas instituições estão engajadas no esforço de aprimorar seus processos com vistas à preservação do meio-ambiente. A comprovação de um comportamento ambiental correto tem ultrapassado os interesses meramente econômicos, e os benefícios advindos das boas práticas ambientais já podem ser mensurados.

Com o advento da globalização e o avanço tecnológico nos meios de produção, surgiram também várias problemáticas atuais, sendo uma delas o mau uso dos recursos naturais, por isso as empresas contemporâneas estão procurando meios de planejamento e gerenciamento de suas atividades como forma de se ajustar à legislação ambiental vigente no país, como também de se destacar no ramo de atividade exercida. Empresários passaram a fazer uso de ferramentas e modelos de gestão que buscavam o controle e a prevenção de danos 
ambientais, na tentativa de responder com maior eficiência às atuais demandas de mercado (DONAIRE, 1999).

Os empresários começam sua responsabilidade a partir do momento que oferecem empregos para a sociedade. Os benefícios oferecidos aos trabalhadores agregam um pacote que oferece proveito para toda a sociedade, pois quando a família adquire renda, gera-se um ciclo onde todos dependem uns dos outros para sobreviver. O Instituto Ethos (2007) afirma que "a responsabilidade social corporativa se dá pelo conjunto de ações que geram benefícios à sociedade”. Isso requer conhecimento de seus gestores, o que inclui o papel das instituições de ensino superior na formação desse profissional contemporâneo com práticas inovadoras para gerir e desenvolver pessoas e recursos (SOUZA, 2014).

Para Machado (2011, p. 11), “O afastamento do Estado na função de provedor do bem-estar social fez com que as empresas percebessem que também são responsáveis pela situação de exclusão e injustiça social criada por essa mudança de paradigma.” Tal percepção em relação às necessidades sociais faz com que as organizações estrategicamente se posicionem a fim de preencher ou diminuir as lacunas deixadas pelo Estado.

O Pacto Global da Rede Brasileira é uma iniciativa planejada para empresários comprometidos em alinhar suas operações e estratégias atuando em quatro temas, dentre eles o meio ambiente, que traz três princípios: 1) de que as empresas devem apoiar as abordagens preventivas aos desafios ambientais; 2) desenvolver iniciativas para promoção de maior responsabilidade ambiental e; 3) incentivar o desenvolvimento e a difusão de tecnologias ambientalmente sustentáveis, ou seja, fazer com que os principais agentes do desenvolvimento econômico, prosperem com práticas de produção e de prestação de serviços, capazes de suprir as necessidades dos consumidores atuais sem que esse desenvolvimento acabe com os recursos das gerações futuras.

A proposta da prática da sustentabilidade empresarial envolve desde a origem dos insumos utilizados, passando pelo processo de 
produção (de forma econômica) até o descarte do produto após o uso, as famosas embalagens. Fabricar produtos ou prestar serviços que não degradem o meio ambiente são iniciativas que todo empresário deve apresentar, seja ele de pequeno, médio, grande porte, ou até mesmo o microempreendedor individual.

\section{Práticas extensionistasatravés da academia}

Desde o primeiro semestre do ano de 2010 (2010.1), a disciplina Direito Empresarial do curso de Administração da Faculdade de Tecnologia e Ciências é responsável por suscitar nos discentes a necessidade de levá-los a pensar em práticas extensionistas que contribuíam para uma melhor compreensão do conteúdo programático da disciplina, bem como a relação entre teoria e prática no contexto organizacional. Nesse sentido, semestralmente discentes do IV semestre são convidados através de projetos de extensão a beneficiar a comunidade por meio de atividades como campanhas, oficinas, encontros, palestras que abordem assuntos relacionados à gestão/administração.

Nas últimas noveedições dos projetos de extensão realizados foram discutidos temas como ética e concorrência, marketing enquanto ferramenta inimiga ou aliada, assédio moral nas organizações, gestão e solidariedade, dentre outros. Cada projeto teve como público alvo empresários de pequeno porte, microempresários individuais, bem como pessoas físicas autônomas que exerciam alguma prática empresarial (na condição de empresários de fato) no município de Vitória da Conquista e nas cidades circunvizinhas.

No semestre 2014.2, a $10^{\mathrm{a}}$ edição do projeto aqui apresentado - Sustentabilidade Empresarial - Um conceito para toda a vida - devido à temática, ratificou seu caráter interdisciplinar envolvendo a disciplina Direito Empresarial e a disciplina Meio Ambiente e Sociedade.

A problemática suscitada decorre da proximidade de inauguração do novo Centro de Comércio Popular da cidade de Vitória da Conquista, que receberá os 260 proprietários de boxes da antiga "Feira do 
Paraguai". Questiona-se sobre o uso sustentável do novo espaço físico onde esses microempreendedores exercerão suas atividades. Desse modo, surgiu a ideia da $1^{a}$ Mobilização em prol da Sustentabilidade Empresarial - Um conceito para toda a vida, a fim desensibilizar aqueles microempreendedores acerca do pensamento sustentável que contribua para estimular tais práticas.

O objetivo principal deste projeto é partilhar informações sobre o destino correto dos resíduos produzidos, estimulando a reciclagem do lixo (a coleta seletiva, o aproveitamento de partes normalmente descartadas), pontos de coleta de lixo eletrônico, a prevenção contra desperdícios de água, matérias-primas, energia elétrica. Enquanto objetivos específicos pretendem despertar nos microempreendedores da "Feira do Paraguai" o interesse pela sustentabilidade empresarial; esclareceracerca da existência do conceito de sustentabilidade empresarial; buscar aproximar a comunidade discente da teoria e prática, levando os conhecimentos aprendidos na sala de aula para a sociedade; elaborar e distribuir uma cartilha sobre sustentabilidade empresarial; dialogar com os microempreendedores sobre sustentabilidade empresarial e incutir nos microempreendedores o desejo de continuar o aprendizado.

\section{Método}

Para subsidiar as ações propostas através da extensão, a princípio optou-se por estudo exploratório descritivo a fim de aproximar a um marco teórico que pudesse fundamentar as discussões propostas, bem como conhecer e descrever a realidade que sofrerá a intervenção. Em um segundo momento, foi elaborado o projeto e submetido ao Núcleo de Extensão da Instituição para aprovação. Munidos de cronograma, as etapas seguintes estão relacionadas à elaboração de uma cartilha com base no modelo do Serviço Social da Indústria (SESI) que aborda questões relacionadas à responsabilidade social e cidadania. A cartilha terá 6 páginas, frente e verso, e será impressa em papel reciclado, cujas dimensões serão $148 \mathrm{~mm}$ x $210 \mathrm{~mm}$. No semestre 2015.1 a cartilha também será lançada em meio eletrônico. 
Embora a iniciativa seja dos discentes do curso de Administração da FTC, a participação no evento está aberta aos estudantes do curso de Administração das demais faculdades da cidade. A inscrição está condicionada à doação de $1 \mathrm{~kg}$ de alimento não perecível, que será recolhido no dia do evento e repassado posteriormente para as novas instalações do Albergue Nosso Lar, casa de amparo aos idosos, mantida pela União Espírita de Vitória da Conquista.

A mobilização acontecerá no dia 22 de novembro de 2014 das $8 \mathrm{~h}$ da manhã ao meio dia, na Feira do Paraguai, localizada na Praça Hercílio Lima, Bairro São Vicente. Durante a mobilização todos os envolvidos estarão trajados de branco, com o símbolo do projeto afixado na camisa. As cartilhas serão distribuídas para todos os feirantes, que também receberão o adesivo da mobilização.

Figura 1 - Cartilha $1^{\text {a }}$ Mobilização de Sustentabilidade Empresarial

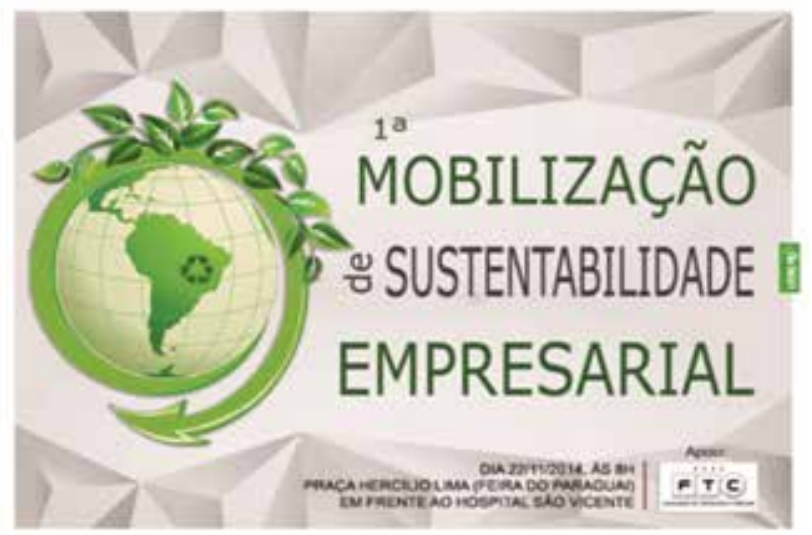

Fonte: Elaboração própria (2014).

Importante ressaltar que, durante a entrega da cartilha, os discentes irão dialogar com os feirantes sobre sustentabilidade empresarial e convidá-los para a $2^{a}$ etapa da mobilização que ocorrerá no primeiro semestre letivo do ano de 2015, em 2015.1. Nessa $2^{a}$ etapa, os feirantes beneficiados serão convidados a assistir a uma mesa redonda intitulada Empreendedorismo, Direito e Responsabilidade Socioambiental, com 
intuito de discutir o perfil empreendedor da atualidade, legislação ambiental e o papel de microempreendedores diante tal realidade.

Tendo em vista que se trata de ação extensionista continuada, a retroalimentação entre pesquisa e extensão ocorrerá por meio da ampliação de questionário fechado no dia de realização da mesa redonda, com intuito de identificar se o objetivo geral do projeto foi alcançado. Desse modo, pretende-se aliar teoria e prática e ampliar a ideia de que os acadêmicos devem participar ativamente da sociedade e com ela colaborar, desenvolvendo assim a função social do ensino superior.

\section{A feira do Paraguai e as futuras instalações do Centro de Comércio Popular}

A Realidade acerca dos comerciantes da Feira do Paraguai na atualidade corresponde a 260 feirantes alocados em boxes não padronizados, construídos na Praça Hercílio Lima. Não há qualquer tipo de preocupação com a sustentabilidade ambiental.

Não há coleta seletiva de lixo, nem banheiros públicos, preocupação com a economia de energia e água.

Figura 2 - Instalações provisórias da Feira do Paraguai

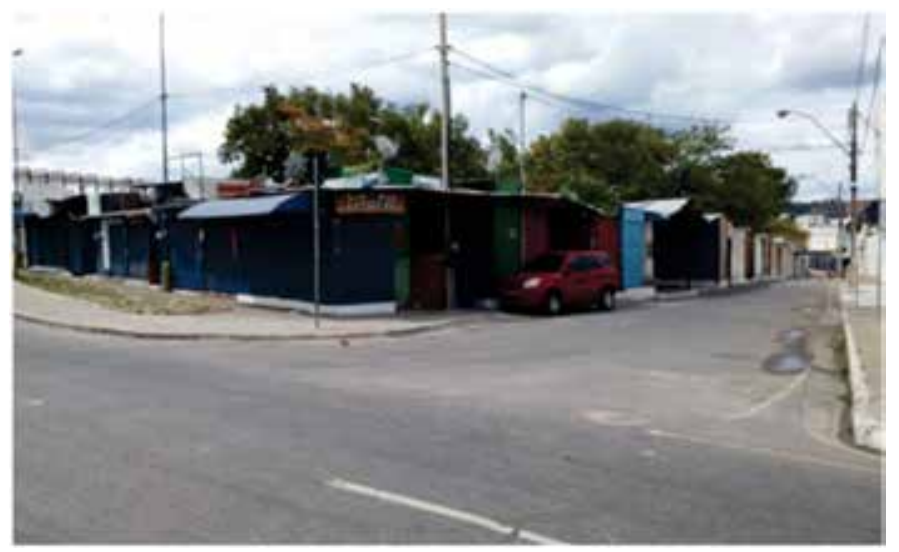

Fonte: Foto dos autores (2014). 
Figura 3 - Instalações provisórias da Feira do Paraguai

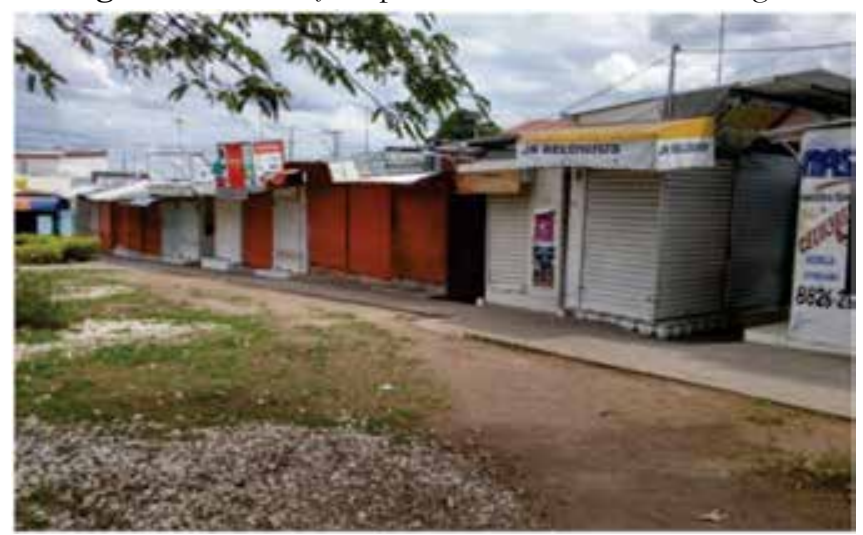

Fonte: Foto dos autores (2014).

O novo Centro de Comércio popular fica localizado na Av. Crescêncio Silveira, no centro de Vitória da Conquista, e contará com 300 lojas padronizadas. Embora ainda não esteja aberto à visitação pública é possível já avistar pelo lado de fora coletores padronizados para coleta seletiva e clara boia que provavelmente trará maior iluminação natural e provável redução de energia elétrica.

Figura 4 - Instalações provisórias da Feira do Paraguai

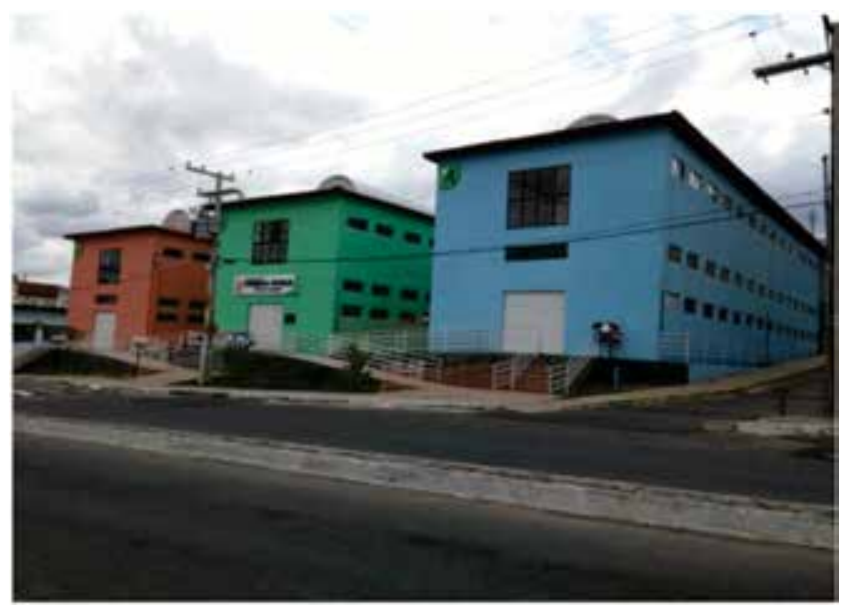

Fonte: Foto dos autores (2014). 
Espera-se que o novo espaço contribua para o comércio de Vitoria da Conquista, haja vista que a prática de comércio popular é uma realidade no município, e que os comerciantes ali instalados possam valorizar o novo espaço físico e busquem medidas de preservação, garantindo assim não só a sustentabilidade ambiental, mas também a empresarial.

\section{Resultados esperados}

Em primeiro lugar é preciso esclarecer que os resultados esperados devem ser observados sob 4 (quarto) prismas: 1) para os discentes envolvidos; 2) para os feirantes da Feira do Paraguai (microempreendedores); 3) para a comunidade local; 4) para a instituição de ensino superior.

Ao analisar os resultados esperados sob o primeiro prisma, almejase a concretização da interdisciplinaridade entre Direito Empresarial e Meio Ambiente e Sociedade, demonstrando que a preocupação com a sustentabilidade deve representar para o empresário o conceito de investimento e não o conceito de despesa, indo ao encontro da finalidade empresarial que é o lucro, sem olvidar a preservação do meio ambiente.

Ainda como resultados esperados para os discentes, destaca-se a conciliação entre teoria e prática, aproximando o estudante da realidade que o espera na futura atuação profissional. E, por fim, atribuir função social ao ensino superior que recebem.

Sob o segundo prisma (o dos microempreendedores), espera-se "plantar a semente" da consciência sustentável. Já que o presente projeto terá execução continuada, as demais etapas dele servirão de "adubo" a fim de possibilitar o desenvolvimento da ideia de sustentabilidade empresarial.

O Centro de Comércio Popular, como ideia inovadora na cidade, pede uma postura inovadora dos beneficiados (microempreendedores), pautada em condutas sustentáveis como o correto trato dado ao lixo, à água e a energia elétrica. 
Em relação ao terceiro prisma, a comunidade local, a expectativa é o reflexo direto que a postura correta dos microempreendedores trás na vida de todos, já que o que está em jogo é o meio ambiente. Práticas empresariais sustentáveis também requerem um consumo sustentável. Por fim, o quarto prisma, refere-se à contribuição do ensino superior eao retorno à comunidade, não somente pela sensibilização em relação ao meio ambiente e sustentabilidade, como também a doação dos alimentos ao Albergue Nosso Lar

Enfim, vários são os envolvidos direta ou indiretamente no projeto, e os resultados podem ter comutatividade e atingir não só os acadêmicos, quanto os feirantes e toda a comunidade local.

\section{Referências}

BRASIL. Presidência da República. Casa Civil. Subchefia para Assuntos Jurídicos. Lei n. 9.795, de 27 de abril de 1999. Dispõe sobre a educação ambiental. Política Nacional de Educação Ambiental. Brasília, 1999. Disponível em: < http://www.planalto.gov.br/ccivil_03/leis/19795.htm>. Acesso em: 7 nov. 2014.

DONAIRE, Denis. Gestão ambiental na empresa. São Paulo: Atlas, 1999.

INSTITUTO ETHOS. Métodos e técnicas de coleta de dados que utilizamos. Disponível em: < http://www.ethos.com.br/home/conteudo/4213/4848/ Metodos-e-Tecnicas>. Acesso em: 05 nov. 2014.

MACHADO, Olavo Júnior. A empresa como fator de desenvolvimento do território: responsabilidade social e terceiro setor. Belo Horizonte: Fundação AVSI, 2011. Disponível em: <http://www.avsi.org/wpcontent/uploads/2012/10/Livro-AVSI-Responsabilidade-SocialFINAL.pdf $>$. Acesso em: 29 out. 2014.

KOTLER, Philip. Marketing. São Paulo: Atlas/Editora Compacta, 1996. Disponível em: < http://www.spositoonline.com.br/imagens/professor/ marketing_philip_kotler.pdf $>$. Acesso em: 6 nov. 2014. 
PACTO GLOBAL DA REDE BRASILEIRA. Disponível em: < http:/ / www.pactoglobal.org.br/>. Acesso em: 4 nov. 2104.

SOUZA, Renato Santos de. Evolução e condicionantes da gestão ambiental nas empresas. REAd - Revista Eletrônica de Administração, Santa Maria, RS: Escola de Administração, Universidade Federal do Rio Grande do Sul, v. 8, n. 6, p. 1-22, nov./dez. 2002. Disponível em: $<$ http://seer.ufrgs.br/index.php/read/article/view/42728/27083>. Acesso em: 2 nov. 2014. 